\title{
Application of EIQ Method in Distribution Center Planning
}

\author{
Hou Mingqian ${ }^{1, \mathrm{a},{ }^{*}}$, Tian Xin ${ }^{1, \mathrm{~b}}$, Dong Nan ${ }^{1, \mathrm{c}}$, Geng Yuxue ${ }^{1, \mathrm{~d}}$, Wang Xinwu ${ }^{1, \mathrm{e}}$ \\ ${ }^{1}$ Logistics Department, Shandong Jiaotong University, Jinan, Shandong Provience, 250357, China
}

\begin{abstract}
Through the EIQ analysis of the quantity of goods out of storage, the present situation of logistics distribution center is effectively displayed, a better picking method is obtained, and the optimal placement method is found by using the ABC classification method combined with the data. The efficiency of logistics distribution center is greatly improved.
\end{abstract}

\section{Introduction}

The logistics distribution center is responsible for the tasks of purchase, goods classification, storage, sorting, delivery and information processing, which plays a vital role in the whole supply chain. With the development of user orders in the direction of small batch, high frequency and multi variety, the quantity and item differentiation of distribution center orders become more and more obvious, and the equipment inside the distribution center often can not fit well in the sorting strategy, which reduces the operation efficiency and the overall service level. Using EIQ methods and PCB tables to design, manage and operate standard distribution centers is a common method. The so-called standard distribution center refers to the storage distribution center, which usually involves receiving, storage, order picking, inspection, packaging and transportation of goods. This paper explains an abstract analysis and design method of distribution center based on EIQ method and PCB table, applies this theory to the daily management and operation of distribution center, and solves the application problem of selecting loading and unloading equipment through fuzzy theory.

\section{EIQ Analysis And Its Role}

EIQ analysis, using "E", "I", "Q" these three key elements of logistics to study the demand characteristics of distribution center, to provide planning basis for distribution center. The theory was put forward and actively popularized by Mr. Suzuki, Japan. The E means "Entry", I means" Item", Q means "Quantity". That is, from the customer order items, quantity, order times and other aspects, distribution characteristics and shipping characteristics analysis. EIQ analysis categories include: EQ analysis, understanding order quantity distribution, order processing principles, sorting system planning, and affecting the mode of shipment and shipping area planning, usually based on a single business day EQ analysis; EN analysis: understanding the distribution of order items, analysis of product importance and volume scale, can be used for storage system planning, storage space estimation, and affect sorting methods and sorting area planning; IQ analysis: understanding the quantity of each item has a great impact on the order processing principle and the planning of the sorting system, and will affect the mode of shipment and the planning of the shipping area; IK analysis: it is helpful to understand the frequency of each item. According to the results of the above four analysis projects, provide planning basis for distribution center. Moreover, IQ and IK analysis can also be used as reference for $\mathrm{ABC}$ classification in inventory management.

So, what are the main uses of EIQ analysis? The main purpose of EIQ analysis is to obtain customer order characteristics, purchase and delivery characteristics of logistics distribution center through order content analysis, that is, customer order type, quantity, time of demand, etc. Therefore, EIQ analysis is of great significance. Specifically, the role of EIQ analysis is mainly manifested in the following aspects:

1. Grasping the important customer and demanding characteristics through EIQ analysis can understand the customer's order quantity, which is a large number of sales of the best-selling, which is unsalable. At the same time can also provide customer characteristics of the product and sales area data.

2. Determining the characteristics of item requirements and picking methods by IQ analysis and IK analysis, we can understand the distribution of each product item out of the warehouse, as a reference for product storage, picking, classification, and provide product growth or unsalable situation.

3. Calculating the total shipment average of inventory and related work space demand IQ multiplied by the number of items, the total inventory demand can be estimated by multiplying the number of inventory days,

\footnotetext{
* Corresponding author: a613555576@qq.com

b2911971086@qq.com

c3158401648@qq.com

d1942853206@qq.com

e2609300611@qq.com
} 
and the EQ average quantity multiplied by the number of orders. Can estimate the distribution vehicle demand or stock area space.

4. Storage planning and management are carried out to calculate the storage planning of the warehouse from the EIQ analysis data, so that the storage space of various products can obtain the best economic benefit in the operation efficiency and space utilization ratio.

5. Through the EIQ analysis of the logistics center, we can compare the efficiency of the logistics operation in each stage, so that we can find the problems and improvement points of the logistics system and avoid the system changing because of the external environment. EIQ analysis is a magic weapon for logistics process optimization.

6. Providing sales or shipping forecast data history EIQ data can be used as an important reference for sales forecast, but also can be used to predict the future logistics flow timely and reasonable to do a good job plan, and then improve inventory turnover, operational efficiency and reduce the delivery lead time.

\subsection{Distribution Centre Selection System Planning}

With the development of customer demand towards small batch and multi-variety, the variety, quantity and frequency of distribution goods in distribution center are increasing, which puts forward higher requirements for sorting strategy and sorting operation ability of distribution center.

(1) When sorting, the goods are sorted out according to the "storage area" of the order, and the "classification" is carried out by the user. Sorting operations actually include "picking" and "sorting" activities, which are driven by orders and aim to correctly and quickly assemble customer order items. Therefore, in the actual distribution center, we must adopt reasonable sorting strategy according to the characteristics and requirements of orders, and improve the sorting efficiency scientifically. At the same time, we must also consider the error rate of sorting, unreasonable operation links and processes, cost and other negative factors, and through the use of optimization techniques and methods to minimize or eliminate such factors.

(2) Distribution center picking system mainly includes: automatic picking system: pallet automatic storage system + conveyor (shuttle), automatic storage system disc-picking machine conveyor, automatic storage system shuttle robot, mobile shelf picking machine conveyor; semi-automatic picking system: automatic warehouse conveyor, horizontal rotary automatic warehouse conveyor, vertical rotary automatic warehouse trolley; manual picking system: pallet type shelf forklift, pallet type shelf forklift (pallet truck), pallet type shelf cage car, pallet type shelf trolley pallet type shelf conveyor.

(3) The application of EIQ analysis in the design of distribution center picking system: in the design of logistics system and distribution center system, especially in the design of picking system, we often use EIQ analysis method. By using EIQ analysis, we can correctly select the picking method, calculate the number of picking operators, and select logistics equipment reasonably, so as to improve the productivity of distribution center.

\section{Application of Distribution Centre Planning Analysis}

\subsection{IQ-ABC analysis}

Goods of varying sizes require different levels of manual, mechanized and automated storage shelf systems and handling, picking equipment. For the same storage and transportation operation, the quantity of goods is an important factor affecting the final storage and selection equipment selection. In order to ensure the optimal system of distribution center. The nature of the shipment can be divided into $\mathrm{A}, \mathrm{B}, \mathrm{C}$ three categories.IQ $\mathrm{ABC}$ analysis, similar to inventory $\mathrm{ABC}$ analysis, different categories determine the variety of goods and logistics. See Table 1.

Table 1.IQ-ABC Analysis

\begin{tabular}{|l|c|c|}
\hline & $\begin{array}{c}\text { IQ-ABC } \\
\text { analysis } \\
(\%)\end{array}$ & $\begin{array}{c}\text { Total shipments } \\
\text { Percentage of quantities } \\
(\%)\end{array}$ \\
\hline A category & 10 & 70 \\
\hline B category & 20 & 20 \\
\hline C category & 70 & 10 \\
\hline
\end{tabular}

And IQ analysis shows the flow of goods in the distribution center. The classification of the A、B、C of the goods by IQ analysis for a preliminary determination of the degree of automation and basic types of equipment for the storage, sorting and handling of goods. See Table 2.

Table 2. Effect of IQ on Equipment Decision-making in Distribution Center

\begin{tabular}{|c|c|}
\hline & Main storage and sorting equipment. \\
\hline A category & $\begin{array}{c}\text { High density shelves and automated } \\
\text { storage. }\end{array}$ \\
\hline B category & $\begin{array}{c}\text { Medium density shelves and } \\
\text { mechanized handling equipment. }\end{array}$ \\
\hline C category & $\begin{array}{c}\text { General shelves and manual } \\
\text { selection. }\end{array}$ \\
\hline
\end{tabular}

\subsection{Application of IQ Analysis}

According to the investigation of orders in a distribution center. The distribution center's order for a day is in a relatively stable state. So extract the company's one-day order data and process it. as shown in table 3 
Table 3. EIQ Analysis

\begin{tabular}{|c|c|c|c|c|c|c|c|c|c|c|c|c|c|c|c|c|c|c|c|c|}
\hline E & & & & & & & & & & I & & & & & & & & & EQ & EN \\
\hline E1 & I1 & I2 & I3 & I4 & I5 & I6 & I7 & I8 & I9 & I10 & I11 & I12 & I13 & I14 & I15 & I16 & I17 & I18 & & \\
\hline E2 & 3 & 0 & 5 & 0 & 0 & 7 & 6 & 15 & 5 & 2 & 20 & 6 & 1 & 8 & 4 & 3 & 5 & 8 & 98 & 15 \\
\hline E3 & 4 & 2 & 3 & 2 & 1 & 8 & 11 & 14 & 5 & 0 & 21 & 5 & 2 & 16 & 1 & 1 & 5 & 5 & 106 & 17 \\
\hline E4 & 5 & 0 & 0 & 2 & 2 & 10 & 6 & 11 & 4 & 3 & 23 & 4 & 2 & 6 & 2 & 1 & 5 & 9 & 95 & 16 \\
\hline E5 & 3 & 0 & 2 & 1 & 3 & 11 & 7 & 12 & 4 & 4 & 30 & 4 & 0 & 6 & 3 & 3 & 4 & 11 & 108 & 16 \\
\hline E6 & 4 & 3 & 1 & 3 & 0 & 12 & 5 & 13 & 6 & 0 & 25 & 5 & 2 & 7 & 3 & 2 & 3 & 12 & 106 & 16 \\
\hline E7 & 2 & 0 & 3 & 2 & 2 & 12 & 4 & 13 & 6 & 2 & 22 & 7 & 3 & 7 & 1 & 0 & 4 & 7 & 97 & 16 \\
\hline E8 & 5 & 1 & 4 & 0 & 3 & 13 & 8 & 12 & 7 & 2 & 22 & 8 & 4 & 4 & 4 & 3 & 9 & 7 & 116 & 17 \\
\hline E9 & 0 & 3 & 0 & 2 & 4 & 12 & 11 & 11 & 3 & 1 & 21 & 5 & 2 & 6 & 5 & 2 & 3 & 9 & 100 & 16 \\
\hline E10 & 2 & 0 & 2 & 3 & 2 & 11 & 3 & 15 & 1 & 1 & 19 & 6 & 1 & 7 & 3 & 1 & 6 & 7 & 90 & 17 \\
\hline E11 & 4 & 2 & 2 & 2 & 1 & 14 & 6 & 14 & 2 & 3 & 18 & 6 & 1 & 5 & 4 & 3 & 7 & 8 & 102 & 18 \\
\hline E12 & 1 & 2 & 3 & 2 & 0 & 15 & 5 & 14 & 8 & 2 & 19 & 7 & 2 & 7 & 3 & 3 & 6 & 7 & 106 & 17 \\
\hline E13 & 2 & 3 & 3 & 1 & 0 & 10 & 5 & 11 & 8 & 3 & 20 & 7 & 3 & 9 & 0 & 0 & 4 & 6 & 95 & 15 \\
\hline E14 & 3 & 3 & 1 & 1 & 1 & 10 & 6 & 10 & 7 & 1 & 11 & 5 & 0 & 8 & 1 & 1 & 8 & 5 & 82 & 16 \\
\hline E15 & 3 & 1 & 1 & 2 & 2 & 9 & 5 & 9 & 8 & 0 & 21 & 7 & 1 & 6 & 2 & 0 & 6 & 7 & 90 & 16 \\
\hline E16 & 4 & 0 & 0 & 2 & 0 & 13 & 7 & 11 & 6 & 2 & 17 & 6 & 1 & 8 & 2 & 2 & 7 & 9 & 97 & 15 \\
\hline E17 & 1 & 1 & 2 & 0 & 1 & 11 & 8 & 13 & 3 & 3 & 22 & 6 & 1 & 7 & 3 & 1 & 4 & 7 & 94 & 17 \\
\hline E18 & 2 & 0 & 3 & 0 & 1 & 12 & 9 & 15 & 2 & 3 & 25 & 6 & 2 & 6 & 4 & 4 & 7 & 8 & 109 & 16 \\
\hline E19 & 2 & 2 & 1 & 0 & 2 & 13 & 5 & 14 & 5 & 2 & 23 & 3 & 3 & 4 & 3 & 2 & 7 & 11 & 102 & 17 \\
\hline E20 & 3 & 2 & 1 & 0 & 2 & 11 & 5 & 13 & 6 & 1 & 22 & 4 & 0 & 10 & 3 & 2 & 6 & 8 & 99 & 16 \\
\hline IQ & 53 & 25 & 37 & 25 & 27 & 214 & 122 & 240 & 96 & 35 & 401 & 107 & 31 & 137 & 51 & 34 & 106 & 151 & 1892 & \\
\hline IK & 19 & 13 & 17 & 14 & 15 & 20 & 20 & 20 & 20 & 17 & 20 & 20 & 17 & 20 & 19 & 17 & 20 & 20 & 20 & 309 \\
\hline
\end{tabular}

$\mathrm{I} 1, \mathrm{I} 2, \mathrm{I} 3 \cdots \mathrm{I} 18$ indicates that the items in the customer's order are 18 items ordered by the customer. E1,E2,E3 $\cdots$ E20 indicates the number of orders received from customers within one day. According to the strategy of classified storage, Plato analysis and IQ/IK cross-analysis are carried out.

Plato's analysis is based on the table above, as shown in Fig.1.

\section{Plato's Analysis}

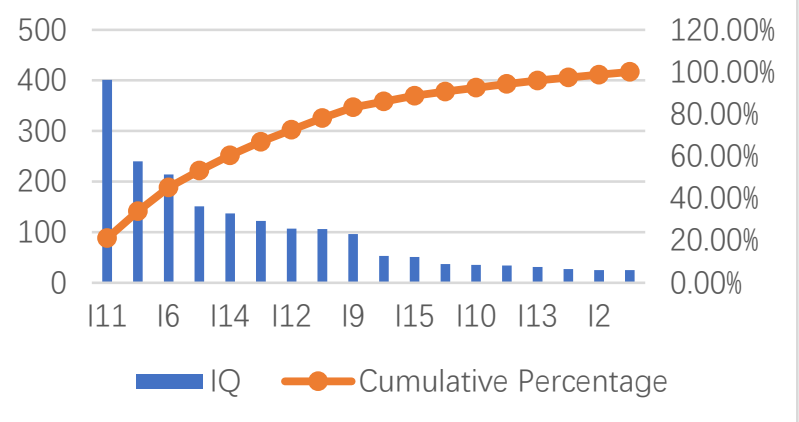

Fig .1. Plato's Analysis

Through the management of ABC classification, it can be found that the number of items I11, I8, I6, I18 the product accounts for $22.2 \%$ of the total number of items, and the cumulative percentage of shipments reaches 53.17, which can be divided into A kinds of products. The number of items I14, I7, I12, I17, I9 the product accounts for $27.78 \%$ of the total number of items, and the cumulative percentage of shipments reaches $30.07 \%$, which is divided into $\mathrm{B}$ kinds of products. I1, of remaining products I15, I3, I10, I16, I13, I5, I2, I4 50\% of the total, The cumulative percentage of shipments was 16.81 percent, Divide it into $\mathrm{C}$ products.

(i) IQ-IK cross-analysis

According to EIQ Analysis IQ-IK cross-analysis. As shown in Fig. 2, it is analyzed.

\section{IQ-IK Cross-analysis Chart}

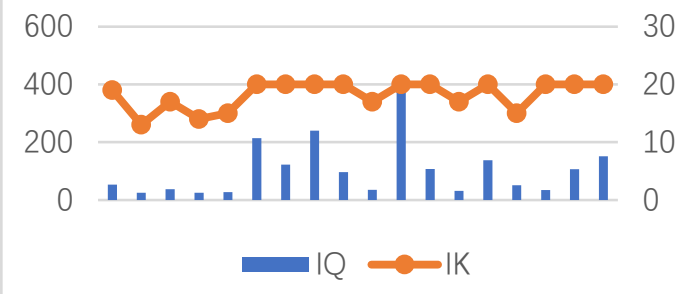

Fig. 2 . IQ-IK Cross-analysis Chart 
IQ-IK the results of cross-analysis, several order picking schemes can be obtained. IQ high: When the IK is high, the order is picked in bulk; if the IK is in the middle, the order is picked separately; Low IK, orders are picked up separately, and concentrated near the entrance and exit position. The IQ is in the middle, if the IK is high, then the order adopts the batch picking method; If the IK is in the middle, pick up the order separately; IK is low, take the order separately as appropriate.IQ low: If the IK is high, then the order is bulk picking; If in the IK, the order is picked separately; IK is low, the order can be divided into sporadic picking area. In this case, the IK high product I6, I7, I8, I9, I11, I12, I13, I14, I16, I17, I18 uses batch picking, the rest is sporadic picking. The general location of the three types of goods is shown in Fig. 3.

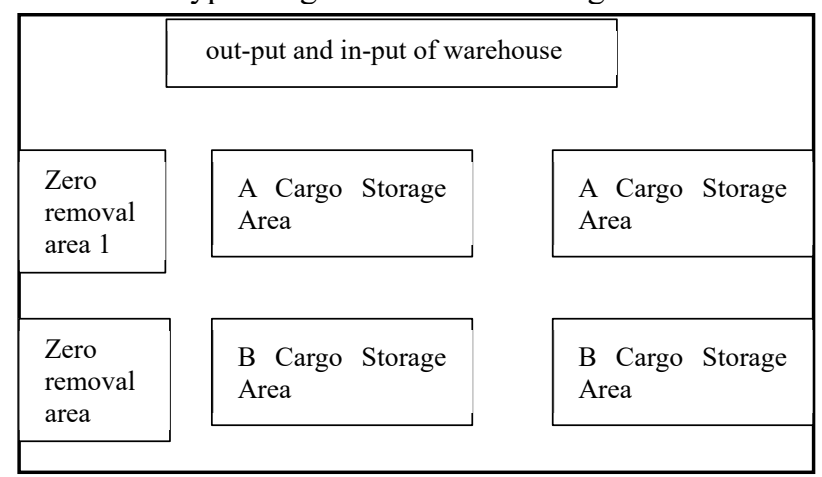

Fig. 3. Product Classification Storage Chart

\subsection{Establishment of Decision Model of Distribution Center Equipment Based on EIQ Analysis}

According to the above analysis, it can be concluded that in the case of distribution center to improve the efficiency of goods picking equipment. According to the order characteristics, matching the appropriate degree of automation, select the appropriate incoming and outgoing picking equipment. As shown in Table 4 below.

Table 4. Distribution Center Equipment Selection Reference

\begin{tabular}{|c|c|c|}
\hline Picking mode & $\begin{array}{c}\text { degree of } \\
\text { automation }\end{array}$ & Out/out/picking equipment \\
\hline \multirow[t]{2}{*}{$\begin{array}{l}\mathrm{P}-\mathrm{C}(\text { zero } \\
\text { removal area })\end{array}$} & automation & $\begin{array}{l}\text { Roadway stacker, } \\
\text { transplanting robot }\end{array}$ \\
\hline & mechanisation & $\begin{array}{l}\text { Forklift forklift, three-way } \\
\text { forklift }\end{array}$ \\
\hline \multirow{3}{*}{$\begin{array}{l}\mathrm{C}-\mathrm{C}(\text { storage } \\
\text { and selection } \\
\text { districts })\end{array}$} & automation & $\begin{array}{c}\text { Transplant robot direct } \\
\text { access conveyor belt }\end{array}$ \\
\hline & mechanisation & $\begin{array}{c}\text { Small Forklift, Sorting } \\
\text { Forklift }\end{array}$ \\
\hline & $\begin{array}{c}\text { manual } \\
\text { operation }\end{array}$ & $\begin{array}{l}\text { Hand-picked trolley or cage } \\
\text { car }\end{array}$ \\
\hline \multirow{2}{*}{$\begin{array}{l}\mathrm{B}-\mathrm{B} \text { ( zero } \\
\text { removal area })\end{array}$} & automation & Conveyor belt shipments \\
\hline & $\begin{array}{c}\text { manual } \\
\text { operation }\end{array}$ & $\begin{array}{l}\text { e-label } \\
\text { picking/picking/picking tags } \\
\text { and trolley, pick-up trolley }\end{array}$ \\
\hline
\end{tabular}

\section{Conclusion}

From the point of view of the item, quantity and order number of customer order, this paper analyzes the shipping characteristics and discusses the operation mode.
Combined with EIQ analysis, historical order data analysis. Including the distribution of various product shipments, as well as the importance of various products and volume scale to obtain the characteristics of the logistics system module. It improves the feasibility and utilization of planning equipment. In the future work, will combine the distribution center other characteristics to establish the model, more comprehensive improvement logistics operation.

\section{References}

1. Zhao, Chen Wenjie. Study on the Model of Sorting Equipment Based on EIQ Analysis Method Mechanical engineering and automation, 2020, (1):137-138. Van der Geer; and J, Hanraads, J.A.J, Lupton, R.A.(2010)The art of writing a scientific article.J.Sci. Commun.,163：51-59.

2. Yang Wei, Cao Jujiang. The Application of EIQ Analysis Method in the Design of Sorting System in Logistics Distribution Center [J] Mechanical Design and Manufacturing ,2006,(9):160-161. DOI : 10.3969/j.issn.10013997.2006.09.069.

3. Xu Futao. Study on the Application of EIQ-ABC Analysis in Distribution Center Storage Allocation [J] of Distribution Center Western.Leather, 2017,39(18): 64-65. DOI: 10.3969/j.issn.1671-1602.2017.18.052.

4. Zhang Tan Jun, Li Wenlong. EIQ Analysis on the Design of Logistics Distribution Center of $[\mathrm{J}]$ Supermarket Logistics Technology, 2016,39(11): 1012.

5. Fan Qiuying, Chen Yanguo. Research on the Application of EIQ-PCB Correlation CrossAnalysis-Taking Small Online Chain Enterprises as Example MarketWeek (Theoretical Research), 2015(09): 15+17.

6. Li Kang. The Application and Research of Cigarette Distribution Center Equipment Selection Based on the Analysis of EIQ Logistics Characteristics [J]. Chongqing and the World ,2011,28(23);118-122.

7. Subir S. Rao, Gajendra K. Adil. Class - Based Storage Assign-ment in a Unit -Load W are house Employing $\mathrm{AS} / \mathrm{RS}$ with Invento-ry Space A lloca tion Considering Product Spec ific Selup to HoldingCost Ratio. Asia - Pacific Journal of Opera tional Research, 2014,31 (5): p22. 